\title{
Psicologia escolar no Brasil: considerações e reflexões históricas
}

\author{
School psychology in Brazil: appreciation \\ and historical reflections
}

\author{
Rejane Maria BARBOSA \\ Clasy Maria MARINHO-ARAÚJO
}

\begin{abstract}
Resumo
O presente artigo apresenta um panorama histórico da psicologia escolar no Brasil desde a transição do século XIX para o XX, com a formação dos primeiros laboratórios de psicologia para estudos de crianças com problemas de aprendizagem, constituídos, principalmente, a partir da influência norte-americana e francesa. Discutem-se, ainda, momentos posteriores de crise, localizados na década de 1980, e a busca por novas bases teórico-metodológicas para a atuação. O artigo está dividido em duas partes: em primeiro lugar, apresentam-se um panorama dos principais fatos históricos e dados de pesquisas acerca das concepções e da atuação em psicologia escolar no cenário brasileiro; posteriormente, discutem-se temas contemporâneos que emergiram a partir de um movimento de ressignificação das práticas de algumas ações que vêm sendo propostas a partir da década de 1990.
\end{abstract}

Unitermos: Psicologia escolar. História da psicologia. Psicólogo educacional.

\begin{abstract}
This article presents an historic overview of School Psychology in Brazil covering the transition between the XIX and XX centuries, with the creation of the first psychology laboratories for studies of children with learning difficulties, mainly resulting from the influence of North America and France. The subsequent period of crisis in the 1980s is also discussed, as is the search for new theoretical and methodological bases for involvement. The article is divided into two parts. First, it presents an overview of the main historical facts and data from research into concepts and involvement in school psychology in the Brazilian setting. Subsequently, contemporary issues are discussed thatemerged from a movement towards the re-signification of the practice of certain actions that have been proposed since the 1990s.
\end{abstract}

Uniterms: School psychology. History of psychology. Educacional psychologists.

Este trabalho apresenta uma revisão bibliográfica sobre a história da psicologia escolar no Brasil, isto é, das construções ocorridas na interface da ciência psicológica com o sistema educacional. Como se verá no decorrer desta exposição, a relação estabelecida entre psicologia e educação revela-se bastante satisfatória para ambas, uma vez que possuem pontos de interesse convergentes, como, por exemplo, a relação entre desenvolvimento e aprendizagem.

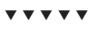

1 Universidade de Brasília, Instituto de Psicologia, Laboratório de Psicogênese. Campus Universitário Darcy Ribeiro, ICC Sul, 70900- 910, Brasília, DF, Brasil. Correspondência para/Correspondence to: C.M. MARINHO-ARAÚJO. E-mail: <claisy@unb.br>.
} 
O artigo apresenta, na primeira seção, fatos históricos ocorridos a partir do século XIX e reflexões acerca das concepções e formas de atuação em psicologia escolar. Na segunda seção, discutem-se temas contemporâneos que emergiram a partir de um movimento de ressignificação das práticas de trabalho do psicólogo escolar, além de ações que vêm sendo propostas em alguns contextos de trabalho a partir da década de 1990.

\section{A trajetória da psicologia escolar no Brasil}

Um dos primeiros movimentos da psicologia escolar no século XIX estava ligado aos trabalhos realizados por Stanley Hall, nos Estados Unidos. Dentre eles, destacam-se a publicação de um artigo no ano de 1882 sob o título: "O conteúdo da mente das crianças quando ingressam na escola", e o surgimento de clínicas e revistas de divulgação de pesquisas ligadas, principalmente, à área da psicometria e da psicologia experimental (Pfromm Netto, 2001).

No cenário europeu, sobressaía a psicologia escolar desenvolvida na França, caracterizada principalmente pela intervenção psicológica junto aos alunos com necessidades escolares especiais e pelos trabalhos desenvolvidos por Alfred Binet, que focalizava, dentre outros objetivos, o desenvolvimento de instrumentos psicométricos capazes de avaliar a inteligência humana (Gomes, 2004).

A psicologia escolar norte-americana e a francesa configuraram-se como as duas principais fontes de influência na área por todo o mundo, inclusive no Brasil. A esse respeito, Campos e Jucá (2006, p.37) comentaram: "(a psicologia escolar no Brasil) se configurou menos como ciência experimental, voltada para a pesquisa básica, produção de conhecimentos, e mais como um campo de aplicação na medicina e na educação. Estava voltada para o trabalho técnico, para a implementação das teorias desenvolvidas em países como os Estados Unidos e os da Europa".

Cruces (2006, p.20) destacou que "a psicologia desenvolveu-se no Brasil principalmente para atender problemas da educação, sobretudo a formação de professores", mas não como área específica de atuação em psicologia escolar (Campos \& Jucá, 2006). Nessa perspectiva, foram criados, em vários estados brasileiros, laboratórios de psicologia ligados às escolas normais, onde eram desenvolvidas pesquisas junto aos alunos com necessidades especiais e dificuldades de aprendizagem (Antunes, 1999).

Durante o período de 1889 a 1930, conhecido como República Velha, instrumentos psicológicos na medição e classificação de indivíduos em instituições médicas e educacionais começaram a ser utilizados em grande escala, o que demonstra a influência da psicologia norte-americana, principalmente no que se refere ao trabalho do psicólogo desenvolvido junto às instituições escolares (Cruces, 2006).

No início da psicologia escolar no Brasil, evidenciou-se o caráter clínico e terapêutico das intervenções realizadas; vale destacar, nesse sentido, o livro de Franco, datado do ano de 1915 e intitulado "Noções de pedagogia experimental", que, além de trazer reflexões sobre as capacidades mentais elementares, apresentava definições de retardatários escolares e comentários acerca da educação especial de deficientes visuais e auditivos em consonância com estudos de Binet, Simon e Pestalozzi (Pfromm Netto, 2001).

Também no início do século XX, Clemente Quaglio realizou pesquisa sobre deficiência mental em escolares, utilizando instrumento de medição da inteligência desenvolvido por Binet e Simon. Laboratórios de psicologia espalhados pelo país produziram diversas pesquisas com foco na medição do desenvolvimento mental, aprendizagem e maturidade para leitura e escrita por meio de testes (Gomes, 2004).

Outros trabalhos, como os realizados pela Seção de Higiene Mental Escolar, subordinada ao Departamento de Educação do Estado de São Paulo, contemplaram o ensino de deficientes mentais e a assistência às "crianças-problema", mantendo o interesse por temas relacionados às dificuldades de aprendizagem.

Porém, se por um lado predominou a concepção clínica e classificatória no tratamento dos problemas de aprendizagem, também estiveram presentes outras concepções que procuravam compreender as relações do indivíduo com o seu contexto social. Dentre os principais representantes de tais ideias, destacaram-se Helena Antipoff, Manoel Bomfim e Aníbal Teixeira (Bock, 1999; Cruces, 2006). 
Portanto, a principal característica da atuação em psicologia escolar durante a primeira metade do século XX foi o caráter remediativo com o qual se tratavam os problemas de desenvolvimento e aprendizagem. Esse fato evidencia a forte influência da medicina e a consolidação de uma atuação clínica no trabalho do psicólogo escolar junto aos contextos educacionais, nos quais se privilegiava o enfoque psicométrico por meio da avaliação da prontidão escolar, da organização de classes para alunos considerados especiais, dos diagnósticos e dos encaminhamentos para serviços especializados (Campos \& Jucá, 2006; Guzzo, 2001).

No âmbito da construção e consolidação da psicologia no cenário brasileiro, os anos de 1960 e 1970, marcados pela movimentação civil em oposição ao regime político, viram acontecer também, dentro da área, reivindicações pela ressignificação da relação da psicologia com a sociedade. Dentre as consequências dessa mobilização está o surgimento de novas áreas de formação e atuação ligadas principalmente à área da saúde e da educação (Campos \& Jucá, 2006).

Os anos de 1970 também se caracterizaram, no âmbito da educação, pela promulgação da lei no 5.692/71, que ampliou o sistema educacional e efetivou a expansão da escolaridade obrigatória e gratuita, trazendo mudanças significativas no contexto escolar. $O$ aumento no quantitativo de alunos advindos das mais diversas realidades socioculturais ocasionou dificuldades de adaptação do sistema à nova realidade, tanto em termos de infraestrutura das escolas quanto em termos de concepções e metodologias de aprendizagem adequadas ao novo panorama educacional. Por conseguinte, observou-se um crescimento da demanda de alunos com dificuldades de aprendizagem que extrapolavam o entendimento e as intervenções pedagógicas dos docentes já adaptadas ao antigo contexto (Marinho-Araújo \& Almeida, 2005).

Diante dessa situação, a psicologia, com seu arcabouço psicométrico e clínico, foi chamada para auxiliar o sistema educacional a fim de se compreenderem as queixas escolares. Tais atividades, específicas do psicólogo, contavam com respaldo científico devido aos critérios de neutralidade, quantificação e classificação, em consonância com a proposta positivista, bastante utilizada na época (Massimi, 1990).
A prática das intervenções acima mencionadas provocou, ao longo das duas décadas seguintes, explicações para o fracasso escolar baseadas nos resultados obtidos por meio de instrumentos de medição da inteligência, atributos afetivos, motores e outros que ora localizavam a problemática no indivíduo, ora relacionavam as dificuldades escolares às condições socioeconômicas e/ou ao ambiente familiar (Collares \& Moysés, 1996; Patto, 1999).

Porém, ao contrário do que pretendiam os psicólogos - esclarecer as causas e tratar as dificuldades de aprendizagem -, tais intervenções trouxeram prejuízos ao desenvolvimento dos alunos e contribuíram para a passividade dos agentes escolares, uma vez que a ideia de melhora associava-se ao poder de cura delegado à medicina e à psicologia (Campos \& Jucá, 2006; Maluf, 2001).

Assim, a psicologia alcançou reconhecimento como detentora de um saber que lhe autorizava explicar o fracasso escolar, destinando-se a atribuição de solucionar as queixas escolares, principalmente por meio do atendimento ao aluno (Kupfer, 2004). Fatores como a interação professor-aluno em sala de aula e a diversificação de estratégias de ensino que consideram aspectos peculiares do contexto sociocultural e escolar do aluno continuaram não se configurando como relevantes para a compreensão das dificuldades de aprendizagem.

Diante do exposto, constata-se que a relação da psicologia com a educação aconteceu de forma assimétrica, pois aquela explicava os fenômenos e ditava procedimentos de tratamento, contribuindo para processos de categorização, segregação e marginalização do que é considerado "diferente" (Marinho-Araújo \& Almeida, 2005; Neves, 2005; 2001).

A insatisfação dos psicólogos escolares com sua atuação no final da década de 1970 provocou uma crise que se prolongou pelas duas décadas seguintes. Esse período se caracterizou pela produção de reflexões e pesquisas que evidenciavam os entraves causados por concepções remediativas e circunstanciais aplicadas ao processo educativo, além de repercussões que originaram desestabilização e insegurança na atuação em psicologia escolar, uma vez que os procedimentos convencionais não mais respondiam com eficácia às demandas do contexto. 
O avanço das discussões propiciou, no final dos anos de 1980 e início da década de 1990, a criação da Associação Brasileira de Psicologia Escolar e Educacional (ABRAPEE), acontecimento importante para a delimitação da área de psicologia escolar. A entidade vem contribuindo, desde então, com a divulgação de reflexões acerca da identidade do psicólogo escolar, dos conhecimentos psicológicos que se aplicam à área e das possibilidades de atuação em espaços educacionais.

Vale destacar, ainda, que a partir dos anos de 1990, a Associação Nacional de Pesquisa e Pós-Graduação em Psicologia (ANPEPP) vem produzindo uma intensa discussão acerca da atuação em psicologia escolar por meio do Grupo de Trabalho (GT) de Psicologia Escolar: pesquisa, formação e prática, que investiga e produz reflexões teóricas e interventivas acerca da psicologia escolar.

Uma análise de publicações veiculadas por essas instituições, e ainda de outros trabalhos, explicitou o incômodo com práticas psicológicas discriminatórias e individualizantes no contexto escolar (Almeida, 2002; Cruces, 2006; Kupfer, 2004; Patto, 1999; Senna \& Almeida, 2005; Souza, 2004). Dessa forma, tornava-se evidente a necessidade de rever concepções e procedimentos, devendo ocorrer uma mudança na forma como o psicólogo escolar atuava, então baseada em um modelo clínico, que, segundo Souza (2004, p.35):

\footnotetext{
... é o reflexo de uma visão de mundo que explica a realidade a partir de estruturas psíquicas e nega as influências e/ou determinações das relações institucionais e sociais sobre o psiquismo, encobrindo as arbitrariedades, os esteriótipos e preconceitos de que as crianças das classes populares são vítimas no processo educacional e social.
}

A literatura produzida a partir de 1990 trazia, ainda, muitas publicações acerca das concepções que embasaram a atuação da psicologia escolar no século XX e a necessidade de ressignificação de suas práticas. Dentre os temas, encontravam-se discussões acerca da adoção de uma postura crítica e comprometida com o desenvolvimento social e com a inclusão por parte do psicólogo escolar (Campos, Lopes, Onofre, Alexandre \& Silva, 2005; Guzzo, 2005; Souza, 2004;); da atuação do psicólogo escolar como membro efetivo do contexto educacional (Araújo, 2003; Marinho-Araújo \& Almeida, 2005; Neves \& Almeida, 2006); das reflexões sobre a formação e a atuação do psicólogo escolar na sociedade atual (Mira, Tardin \& Pedroza, 2005).

Recentemente, a partir do ano 2000, observou-se o avanço da discussão teórica acerca da atuação do psicólogo escolar. Dentre os temas contemplados estão a atuação institucional, a participação do psicólogo escolar na formação de professores e na elaboração do projeto político pedagógico da escola e experiências de estágios baseadas em metodologias de pesquisa-ação, por exemplo. Tais trabalhos buscaram uma articulação maior da psicologia com o contexto da escola, demarcando novos focos de intervenção na área (Araújo, 2003; Guzzo, 2001; Guzzo \& Weschler, 2001; Marinho-Araújo, 2007; Marinho-Araújo \& Neves, 2007; Martínez, 2006; 2007; Neves, 2001;2007; Novaes, 2001).

Acerca da atuação da psicologia escolar no cenário brasileiro contemporâneo, Cruces (2006) ressaltou que, em locais como o Distrito Federal, a psicologia escolar dispõe de uma organização mais estruturada, com psicólogos escolares atuando em equipes multidisciplinares de atendimento e apoio ao processo de aprendizagem na rede de ensino público. Esses profissionais contam, ainda, com formação continuada oferecida pela Universidade de Brasília desde 1995 (Araújo \& Almeida, 2006; Marinho-Araújo \& Almeida, 2005; Marinho-Araújo \& Neves, 2007; Neves \& Almeida, 2006).

Entretanto, a autora destacou, também, a realidade na maioria dos demais estados brasileiros, que é bastante diferente: "ainda nos defrontamos também com práticas avaliadoras e classificatórias e somos cobrados para desempenhar este papel em grande parte das instituições educacionais que frequentamos" (Cruces, 2006, p.28).

Com relação a esse assunto, Rossi e Paixão (2006) desenvolveram pesquisa no Distrito Federal com o objetivo de verificar qual a representação social de professores e psicólogos escolares acerca da atuação da psicologia na escola. Os resultados revelaram que, apesar da frequência maior de psicólogos escolares em muitas escolas da rede pública, os professores ainda associavam a atuação psicológica a um trabalho predominantemente clínico e individualizado. Já para os psicólogos escolares, o trabalho relacionava-se mais a questões de prevenção e de desenvolvimento do coletivo (Rossi \& Paixão, 2006).

Outra investigação, realizada no Rio Grande do Norte por Campos e Jucá (2006), a respeito das deman- 
das do mercado para o psicólogo escolar concluiu que, para professores e diretores, a psicologia escolar está vinculada à resolução dos problemas apresentados pelos alunos a partir de um atendimento individualizado.

Acredita-se que a discrepância de opiniões acerca do papel da psicologia escolar se deva ao percurso da psicologia desde seu surgimento até os dias atuais. São muitas as divergências externas e internas à própria área da psicologia escolar. Diante dessa constatação, vale destacar algumas temáticas centrais que vêm ajudando a delinear novas possibilidades de atuação, como as definições de psicologia escolar e psicologia educacional, lócus de atuação do psicólogo escolar e novas possibilidades de ação junto à escola.

\section{Reflexões em psicologia escolar na atualidade}

Como assinalado na seção anterior, a psicologia escolar atravessa uma fase de questionamento acerca da sua atuação, na qual convivem intervenções divergentes; algumas que ainda se coadunam com concepções predominantes na primeira metade do século $X X$ e outras que, de forma inovadora, procuram estabelecer novas ações ao psicólogo escolar junto ao contexto educacional (Campos \& Jucá, 2006; Cruces, 2006).

A esse respeito, Maluf (2001, p.65) afirmou:

É preciso reconhecer que a psicologia convive, neste início de um novo século, com paradigmas diversos inspirados por diferentes concepções do real ... convivemos com profundas discordâncias a respeito do estatuto do saber científico. Este é, em nosso entender, um dos muitos desafios que enfrenta o psicólogo e mais especificamente o psicólogo que trabalha no campo da educação.

Também Marinho-Araújo e Almeida (2005, p.69) destacaram: "É momento da psicologia escolar intensificar reflexões na busca de maior criticidade à sua formação e atuação, diante de um cenário político-econômico que agudiza, ainda que de forma cada vez mais sutil, o controle social e as graves desigualdades que se configuram no panorama histórico atual".

Em consonância com essas afirmações, verificou-se a necessidade de refletir sobre algumas construções teórico-metodológicas atuais, sinalizadas no final da seção anterior, acerca da definição da psicologia e seu trabalho na interface com a educação e ainda so- bre outros assuntos referentes ao lócus de atuação do psicólogo escolar e formas de intervenção no contexto educacional.

Uma primeira questão refere-se à divergência de entendimento sobre os termos psicologia escolar e psicologia educacional. Para alguns estudiosos, trata-se de áreas com especificidades distintas: uma relacionada à produção de conhecimentos psicológicos que se direcionam à educação, e outra, à aplicação dessas construções teóricas junto à comunidade escolar.

De acordo com Martinez (2006), a psicologia escolar é a expressão da psicologia no âmbito educacional, com predominância da aplicação dos saberes psicológicos no processo educativo e, ocasionalmente, com produção científica. Em seu próprio relato: "consideramos a psicologia escolar como um campo de atuação profissional do psicólogo (e eventualmente de produção científica) caracterizado pela utilização da psicologia no contexto escolar, com o objetivo de contribuir para otimizar o processo educativo" (Martinez, 2006, p.107).

Nessa perspectiva, destacaram-se, por exemplo, os trabalhos de participação do psicólogo escolar na elaboração e implantação da proposta pedagógica da instituição escolar. A autora localizou, no desenvolvimento dessa atividade, a aplicação de várias funções específicas do profissional de psicologia, como o trabalho de assessoria psicológica para planejamento, intervenção e avaliação do projeto político-pedagógico (Martínez, 2006).

Outras reflexões da autora relacionaram a atuação do psicólogo escolar ao desenvolvimento da criatividade na escola, verificando como os conhecimentos produzidos a partir da investigação psicológica podem contribuir para uma prática educativa mais produtiva para a formação, nos alunos, das capacidades e características necessárias para desempenho criativo em seus diferentes contextos de atuação, presentes e futuros (Martínez, 2001).

Algumas construções teóricas discutem as consequências da separação da psicologia escolar e da psicologia educacional em duas áreas profissionais distintas: uma de aplicação do saber psicológico à realidade e outra de produção teórica de conhecimentos psicológicos aplicados à educação. A esse respeito, Marinho- 
-Araújo \& Almeida (2005, p.18) comentaram: ... a distinção desses termos (psicologia escolar e psicologia educacional) gera compreensões estanques tanto do exercício profissional do psicólogo na escola, quanto das inúmeras elaborações teóricas necessárias à prática profissional".

De acordo com tais considerações, o entrelaçamento da psicologia escolar com a psicologia educacional, numa perspectiva de produção e aplicação de conhecimento, coaduna-se com uma proposta de imersão do psicólogo escolar pesquisador como membro efetivo no espaço educacional. Tal situação favorece a compreensão das influências sociais, econômicas, culturais e outras no espaço escolar e o entendimento acerca das relações interpessoais entre os atores da escola, instigando o desenvolvimento de pesquisas e a construção de intervenções adequadas à necessidade de cada instituição (Almeida, 2002; Araújo, 2003; Araújo \& Almeida, 2006; Marinho-Araújo \& Almeida, 2005; Marinho-Araújo \& Neves, 2007).

Em acordo com essas proposições, Marinho-Araújo \& Almeida (2005, p.88) defenderam:

Para assegurar o enfrentamento do desafio da construção dinâmica desse perfil, defende-se que o profissional de psicologia precisa estar inserido na instituição escolar como membro efetivo desse universo e não mais como "especialista" que presta eventuais consultorias quando emergem problemas circunstanciais.

A partir dessa tese, as autoras apresentaram diversas possibilidades de intervenção que contemplaram uma atuação institucional e relacional, baseada na participação do psicólogo escolar no cotidiano da escola, para que ele pudesse compreender mais adequadamente os valores e juízos que os atores da escola fazem acerca das situações de sucesso e de fracasso no processo de ensino-aprendizagem e nas interações socioafetivas.

Nessa perspectiva de inserção do psicólogo no contexto escolar, a atuação contempla uma intervenção que permite conhecer substancialmente o contexto educativo por meio da compreensão dos aspectos intersubjetivos presentes na escola. Esse processo se torna possível por meio da escuta clínica e da realização de um mapeamento institucional, que propiciam uma investigação aprofundada dos documentos e diretrizes que orientam as práticas pedagógicas, a dinâmica de trabalho do grupo de professores e demais funcionários, a gestão desenvolvida pela direção da escola, a inter-relação de professores, alunos e pais, entre outros aspectos (Marinho-Araújo \& Almeida, 2005).

A partir da compreensão do contexto escolar, o psicólogo poderá fazer intervenções em espaços coletivos existentes na escola, conselhos de classe, coordenações de professores, reuniões bimestrais de pais e mestres, além de criar outros espaços de discussão, como grupos de professores nos quais seja possível a reflexão sobre as práticas pedagógicas, estudos de caso e aspectos intersubjetivos que permeiam o trabalho da instituição (Almeida, 2001; Araújo, 2003).

Ainda no âmbito da atuação psicológica no contexto escolar, destaca-se o trabalho desenvolvido por Neves (2001), cuja intervenção nas situações de queixa escolar privilegiou a comunicação com professores e pais. A autora elaborou um sistema de atendimento denominado Procedimentos de Avaliação e Intervenção das Queixas Escolares (PAIQUE) que propunha uma escuta e intervenção psicológica, em primeiro lugar, para o sujeito que demandou a queixa, geralmente o professor, e, caso necessário, seriam seguidos outros passos que preveem o envolvimento dos pais e posteriormente do aluno.

A avaliação da intervenção realizada pela autora em 1999, utilizando seu modelo junto ao serviço de atendimento psicopedagógico da Secretaria de Educação do Distrito Federal, alcançou um índice de satisfação equivalente a $81,25 \%$ do total de professoras participantes da nova forma de intervenção nas queixas escolares. Constatou-se, também, que, na maioria dos casos, o atendimento psicológico às queixas escolares findava-se no primeiro nível de intervenção, isto é, no atendimento ao professor (Neves \& Almeida, 2006).

De acordo com as considerações supracitadas, a psicologia escolar passa a ser entendida numa perspectiva relacional e institucional, uma vez que considera para além do atendimento individualizado a alunos com dificuldades de aprendizagem a compreensão do funcionamento da instituição, considerando de que forma a complexa rede de interações no âmbito da instituição contribui ou não para a situação de queixa escolar (Araújo \& Almeida, 2006). 
A atuação do psicólogo escolar, compreendida dessa forma, implica o desenvolvimento de sua identidade profissional a partir da mobilização dos conhecimentos técnicos, características pessoais, experiências profissionais e outros fatores presentes na constituição subjeiva. Assim, faz-se necessário que o psicólogo escolar esteja comprometido com o desenvolvimento dos sujeitos, atores e autores do contexto escolar, podendo utilizar, segundo as autoras, a abordagem de competências na mediação desse desenvolvimento. A respeito da promoção do desenvolvimento de novas habilidades e recursos que favoreçam a atuação do psicólogo escolar, Araújo (2003, p.72) observou: "Defende-se ... que a identidade profissional do psicólogo escolar receba o suporte de uma capacitação continuada em serviço, com o foco no desenvolvimento de competências específicas que visem a uma atuação mais segura, sistematizada e fundamentada na instituição escolar".

Convivem, entretanto, no cenário atual da psicologia escolar concepções divergentes no que se refere à atuação e ao lugar do psicólogo escolar no interior da instituição educacional, como se posicionou Souza (2004, p.157):

Trata-se da discussão a respeito do locus do trabalho psicológico no campo da educação. ... Nessa perspectiva, o focus do trabalho seria a instituição escolar e o locus centrava-se em uma atuação profissional em que o psicólogo desempenharia o papel de assessor na escola e não como psicólogo da escola onde trabalhasse, subordinado à direção escolar.

De acordo com as proposições acima, o serviço de psicologia escolar do Instituto de Psicologia da Universidade de São Paulo vem desenvolvendo intervenções em creches, na pré-escola e em turmas de séries iniciais com o objetivo de combater o fracasso escolar (Machado, 2004; Sayão \& Guarido, 2004), bem como trabalhando na criação e manutenção de espaços terapêuticos para o desenvolvimento infantil, como o"Lugar deVida"(Kupfer, 2004).

Destacam-se, também, as produções científicas veiculadas na revista semestral da ABRAPEE, intitulada "Psicologia Escolar e Educacional", criada em 1996, e os boletins eletrônicos disponíveis a partir do ano de 2004. Dentre os principais temas, encontram-se trabalhos ligados ao desenvolvimento de aptidões, traços de personalidade, estudos de escalas e validação de testes psico- métricos. Outros artigos destacam as relações que ocorrem no contexto educacional e suas implicações para o processo de aprendizagem.

Dentre os assuntos frequentemente veiculados na referida revista, há aqueles que se referem à criatividade e às altas habilidades no contexto educativo (Matos \& Fleith, 2006; Mariani \& Alencar, 2005), à psicologia no ensino superior (Cunha \& Carrilho, 2005; Serpa \& Santos, 2001), eà relação entre aspectos diversos do contexto educacional (Dalsan, 2007), entre outros.

Também a Associação Nacional de Pesquisa e Pós-graduação em Psicologia, particularmente pelo empenho do Grupo de Trabalho Psicologia Escolar/Educacional, constituído em 1994, tem promovido uma densa reflexão acerca da interface da psicologia com a educação. O grupo é composto por professores vinculados a universidades brasileiras que desenvolvem pesquisas e estudos.

As investigações desse GT nutrem o debate articulado da teoria com a realidade, que ocorre principalmente a cada dois anos por ocasião dos Simpósios da Associação, gerando publicações dos temas apresentados. Os livros reúnem concepções teórico-metodológicas diversas sobre a psicologia escolar/educacional e abarca um amplo espectro de trabalhos na área.

Os temas predominantes são a atuação e a formação de psicólogos, correspondendo a mais da metade dos trabalhos publicados (Guzzo, 2002; Marinho-Araújo, 2007; Marinho-Araújo \& Neves, 2007; Martinez, 2007; Neves, 2007; Senna \&Almeida, 2005). Comparecem, também, assuntos como o ensino especial/inclusão (Anache, 2007; Araújo \& Campos, 2007), criatividade (Martínez, 2001; Novaes, 2001), história da psicologia escolar (Cruces, 2006; Pfromm Neto, 2001) e psicologia escolar em contextos educativos diversos (Mira, Tardin \& Pedroza, 2005; Novaes, 2002).

Ainda a respeito das discussões veiculadas nas publicações da ANPEPP, encontram-se, frequentemente, aquelas que tratam do compromisso do psicólogo escolar com questões sociopolíticas. Guzzo (2005) comentou os aspectos sociopolítico-econômicos que interferem no contexto escolar, como, por exemplo, a relevância dada ao mercado em detrimento da pessoa, o que se torna, na maioria das vezes, apenas um meio de multiplicação do capital. A esse respeito, destacou: 
"A mercadoria se reveste de valor e a pessoa perde a importância - passa a ser considerada somente na medida em que possui bens" (Guzzo, 2006, p.18).

Campos et al. (2005) defenderam a criação de espaços para a atuação do psicólogo escolar nos sistemas de ensino público em consonância com outros profissionais que se engajem num pleito pelo combate à violência dentro das escolas, mantendo, assim, um compromisso com a discussão política educacional.

Outros trabalhos procuraram discutir o papel da psicologia escolar na interface da inclusão e o cumprimento dos direitos humanos na escola, questionando de que forma a atuação psicológica poderia contribuir com a investigação de situações de sofrimento e segregação de pessoas portadoras de necessidade especiais (Anache, 2005; 2007).

Como se percebe, a trajetória da psicologia escolar, desde os seus primórdios ligados principalmente a uma concepção remediativa e classificatória, passando por momentos de crise diante da atuação e pela busca pela ressignificação da identidade do psicólogo escolar mediante as demandas sociais, expressa a construção de uma trama teórico-metodológica marcada por características culturais, econômicas e políticas específicas de cada época. Esse fato demonstra a necessidade de ressignificação histórica e periódica das proposições defendidas e das ações empreendidas.

Ao finalizar essa revisão de literatura, bem como as reflexões empreendidas acerca da relação da psicologia com a educação, verificou-se que o contexto atual configura-se como um novo momento da psicologia escolar. Passada a fase mais intensa da crise, novas opções de atuação começam a surgir e o papel do psicólogo escolar é compreendido de forma bastante independente do papel do psicólogo clínico, isto é, uma identidade específica começa a ser consolidada.

A busca pela ressignificação das concepções de intervenção e das práticas do psicólogo escolar com vistas à realização de um serviço que procure trabalhar não mais na remediação das dificuldades de aprendizagem, mas na reflexão, contribuindo, assim, para a transformação do espaço escolar em local de valorização do ser humano, responde a questionamentos e alenta os incômodos. Entretanto, abre espaço a novos desafios e propõe a continuação da tecitura da história da psicologia escolar.

\section{Referências}

Almeida, S. F. C. (2002). O psicólogo no cotidiano da escola: re-significando a atuação profissional. In R. S. L. Guzzo (Org.), Psicologia escolar: LDB e educação hoje (pp.77-90). Campinas: Alínea.

Almeida, S. F. C. (2001). O psicólogo escolar e os impasses da educação: implicações da(s) teoria(s) na atuação profissional. In Z. A. P. Del Prette (Org.), Psicologia escolar e educacional, saúde e qualidade de vida: explorando fronteiras (pp.43-57). Campinas: Alínea.

Anache, A. A. (2007). A pessoa com deficiência mental entre os muros da educação. In H. R. Campos (Org.), Formação em psicologia escolar: realidades e perspectivas (pp.213-243). Campinas: Alínea.

Anache, A. A. (2005). O psicólogo nas redes de serviços de educação especial - desafios em face da inclusão In A. M. Martínez (Org.), Psicologia escolar e compromisso social: novos discursos, novas práticas. Campinas: Alínea.

Antunes, M. A. M. (1999). A Psicologia no Brasil: leitura histórica sobre sua constituição. São Paulo: PUC.

Araújo, C. M. M. (2003). Psicologia escolar e o desenvolvimento de competências: uma opção para a capacitação continuada. Tese de doutorado não-publicada, Universidade de Brasília.

Araújo, C. M. M., \& Almeida, S. F. C. (2006). Psicologia escolar institucional: desenvolvendo competências para uma atuação relacional. In S. F. C. Almeida (Org.), Psicologia escolar: ética e competências na formação e atuação do profissional (pp.59-82). Campinas: Alínea.

Araújo, E. R. \& Campos, H. R. (2007). Como estranhos no ninho: o jeito diferente de viver das pessoas com a síndrome de asperger. In H. R. Campos (Org.), Formação em psicologia escolar: realidades e perspectivas (pp.245259). Campinas: Alínea.

Bock, A. M. B. (1999). A Psicologia a caminho do novo século: identidade profissional e compromisso social. Estudos Psicologia (Natal), 4 (2), 315-329. Recuperado em março 30, 2006, disponível em: http: www.scielo.br/epsic

Campos, H. R. \& Jucá, M. R. B. L. (2006). O psicólogo na escola: avaliação da formação à luz das demandas do mercado. In S. F. C. Almeida (Org.), Psicologia escolar: ética e competências na formação e atuação do profissional (pp.37-56). Campinas: Alínea.

Campos, H. R., Lopes, A. C., Onofre, M. H. L, Alexandre, L. B. G., \& Silva, F. V. C. (2005). Violência na escola: o psicólogo escolar na fronteira da política educacional. In A. M. Martínez (Org.), Psicologia escolar e compromisso social: novos discursos, novas práticas (pp.31-46). Campinas: Alínea.

Collares, C. A. L., \& Moysés, M. A. A. (1996). Preconceitos no cotidiano escolar:ensino emedicalização. São Paulo: Cortez.

Cruces, A. V. V. (2006). Psicologia e educação: nossa história e nossa realidade In S. F. C. Almeida (Org.), Psicologia escolar: ética e competências na formação e atuação do profissional (pp.17-36). Campinas: Alínea. 
Cunha, S. M., \& Carrilho, D. M. (2005). O processo de adaptação ao ensino superior e o rendimento acadêmico. Revista de Psicologia Escolar e Educacional, 9 (2), 215-224.

Dalsan, J. (2007). O enfrentamento do fracasso escolar numa escola pública: análise crítica na perspectiva do cotidiano escolar. Boletim Eletrônico 6. Recuperado em abril 12, 2010, disponível em http://www.abrapee. psc. $\mathrm{br} /$ boletim6.htm

Gomes, W. B. (2004). Avaliação psicológica no Brasil: tests de Medeiros e Albuquerque. Avaliação Psicológica, 3 (1), 59-68.

Guzzo, R. S. L. (2001). Saúde psicológica, sucesso escolar e eficácia da escola: desafios do novo milênio para a psicologia escolar. In Z. A. P. Del Prette (Org.), Psicologia escolare educacional, saúde equalidade de vida: explorando fronteiras (pp.25-42). Campinas: Alínea.

Guzzo, R. S. L. (2002). Novo paradigma para a formação e atuação do psicólogo escolar no cenário educacional brasileiro. In R. S. L. Guzzo (Org.), Psicologia escolar: LDB e educação hoje (pp.131-144). Campinas: Alínea.

Guzzo, R. S. L. (2005). Escola amordaçada: compromisso do psicólogo com este contexto. In A. M. Martínez (Org.), Psicologia escolar e compromisso social: novos discursos, novas práticas (pp.17-29). Campinas: Alínea.

Guzzo, R. S. L. (2006). Educação para a liberdade, psicologia da libertação e psicologia escolar: uma práxis para a liberdade. In S. F. C. Almeida (Org.), Psicologia escolar: ética e competências na formação e atuação do profissional (pp.169-178). Campinas: Alínea.

Guzzo, R. S. L., \& Wechsler, S. M. (2001). O psicólogo escolar no Brasil: padrões, prática e perspectivas. In R. S. Lobo (Org.), Psicologia escolar: padrões e práticas em países de língua espanhola e portuguesa (pp.39-46). Campinas: Átomo.

Kupfer, M. C. M. (2004). O que toca à/a psicologia escolar. In A. M. Machado \& M. P. R. Souza (Orgs.), Psicologia escolar: em busca de novos rumos (pp.55-65). São Paulo: Casa do Psicólogo.

Machado, A. M. (2004). Relato de uma intervenção na escola pública. In A. M. Machado \& M. P. R. Souza (Orgs.), Psicologia escolar: em busca de novos rumos (pp.93-106). São Paulo: Casa do Psicólogo.

Maluf, M. R. (2001). O psicólogo escolar e a educação: uma prática em questão. In Z. A. P. Del Prette (Org.), Psicologia escolareeducacional, saúde equalidade devida: explorando fronteiras (pp.59-71). Campinas: Alínea.

Mariani, M. F. M., \& Alencar, E. M. L. S. (2005). Criatividade no trabalho docente segundo professores de história: limites e possibilidades. Revista de Psicologia Escolar e Educacional, 9 (1), 27-36.

Marinho-Araújo, C. M. (2007). A psicologia escolar nas diretrizes curriculares: espaços criados, desafios instalados. In H. R. Campos (Org.), Formação em psicologia escolar: realidades e perspectivas (pp.17-48). Campinas: Alínea.

Marinho-Araújo, C. M., \& Almeida, S. F. C. (2005). Psicologia escolar:construção e consolidação daidentidade profissional. Campinas: Alínea.
Marinho-Araújo, C. M., \& Neves, M. M. B. J. (2007). Psicologia Escolar: perspectivas e compromissos na formação continuada. In H. R. Campos (Org.), Formação em psicologia escolar: realidades e perspectivas (pp.49-67). Campinas: Alínea.

Martínez, A. M. (2001). La interrelación entre investigación psicológica y práctica educativa: um análisis crítico a partir del campo de la creatividad. In Z. A. P. Del Prette (Org.), Psicologia escolar e educacional, saúde e qualidade de vida: explorando fronteiras (pp.87-112). Campinas: Alínea.

Martínez, A. M. (2006). O psicólogo na construção da proposta pedagógica da escola: áreas de atuação e desafios para a formação. In S. F. C. Almeida (Org.), Psicologia escolar: ética e competências na formação e atuação do profissional (pp.105-124). Campinas: Alínea.

Martínez, A. M. (2007). O psicólogo escolar e os processos de implantação de políticas públicas: atuação e formação. In H. R. Campos (Org.), Formação em psicologia escolar: realidades e perspectivas (pp.109-133). Campinas: Alínea.

Massimi, M. (1990). História da psicologia brasileira. São Paulo: Pedagógica e Universitária.

Matos, D. R., \& Fleith, D. S. (2006). Criatividade e clima criativo entre alunos de escolas abertas, intermediárias e tradicionais. Revista de Psicologia Escolar e Educacional, 10 (1), 109-120.

Mira, M. H. N., Tardin, R. M. M., \& Pedroza, E. M. (2005). Alternativas de atuação da psicologia escolar junto à terceira idade. In A. M. Martínez (Org.), Psicologia escolar e compromisso social: novos discursos, novas práticas (pp.95-114). Campinas: Alínea.

Neves, M. B. J. (2001). A atuação da psicologia nas equipes de atendimento psicopedagógico da rede pública de ensino do Distrito Federal. Tese de doutorado não-publicada, Universidade de Brasília.

Neves, M. M. B. J. (2005). Por uma psicologia escolar inclusiva. In A. M. Machado, A. J. V. Neto, M. M. B. J. Neves, M. V. O. Silva, R. G. Prieto, W. Rannã \& E. Abenhaim (Orgs.), Educação inclusiva: direitos humanos na escola (pp.107123). São Paulo: Casa do Psicólogo.

Neves, M. M. B. J. (2007). Formação inicial em psicologia escolar. In H. R. Campos (Org.), Formação em psicologia escolar: realidades e perspectivas (pp.49-67). Campinas: Editora Alínea.

Neves, M. M. B. J., \& Almeida, S. F. C., (2006). A atuação da psicologia escolar no atendimento aos alunos encaminhados com queixas escolares. In S. F. C. Almeida (Org.), Psicologia escolar:ética e competências na formação e atuação do profissional (pp.83-103). Campinas: Alínea.

Novaes, M. H. (2001). Modelos interpretativos da criatividade e alternativas de atuação psicossocioeducativa. In Z. A. P. Del Prette (Org.), Psicologia escolar e educacional, saúde e qualidade de vida: explorando fronteiras (pp.75-86). Campinas: Editora Alínea.

Novaes, M. H. (2002). A convivência em novos espaços e tempos educativos. In R. S. L. Guzzo (Org.), Psicologia 
escolar: LDB e educação hoje (pp.91-102). Campinas: Alínea.

Patto, M. H. S. (1999) A produção do fracasso escolar: histórias de submissão e rebeldia. São Paulo: Casa do Psicólogo.

Pfromm Netto, S. (2001). As origens e o desenvolvimento da psicologia escolar. In S. M. Wechsler (Org.), Psicologia escolar: pesquisa, formação e prática (pp.21-38). Campinas: Alínea.

Rossi, T. M. F., \& Paixão, D. L. L. (2006). Significações sobre a atuação do psicólogo escolar. In S. F. C. Almeida (Org.), Psicologia escolar: ética e competências na formação e atuação do profissional (pp.147-166). Campinas: Alínea.

Sayão, Y. \& Guarido, R. L. (2004). Intervenção psicológica em creche/pré-escola. In A. M. \& M. P. R. Souza (Orgs.), Psicologia escolar: em busca de novos rumos (pp.83-91). São Paulo: Casa do Psicólogo.
Senna, S. R. C. M. \& Almeida, S. F. C. (2005). Formação e atuação do psicólogo escolar da rede pública de ensino do Distrito Federal. In A. M. Martínez (Org.), Psicologia escolare compromisso social:novos discursos, novas práticas (pp.199-230). Campinas: Alínea.

Serpa, M. N. F., \& Santos, A. A. A. (2001). A atuação no ensino superior: um novo campo para psicólogo escolar. Revista de Psicologia Escolar educacional, 5 (1), 37-36.

Souza, M. P. R. (2004). A queixa escolar e o predomínio de uma visão de mundo. In A. M. \& Machado P. R. Souza (Orgs.), Psicologia escolar: em busca de novos rumos (pp.17-37). São Paulo: Casa do Psicólogo.

Recebido em: 18/6//2008

Versão final reapresentada em: 8/2/2010

Aprovado em: 19/2/2010 